\title{
Midnight sinking behaviour in Calanus finmarchicus: a response to satiation or krill predation?
}

\author{
G. A. Tarling ${ }^{1,3, *}$, T. Jarvis ${ }^{2}$, S. M. Emsley ${ }^{3}$, J. B. L. Matthews ${ }^{3}$ \\ ${ }^{1}$ British Antarctic Survey, High Cross, Madingley Road, Cambridge CB3 0ET, United Kingdom \\ ${ }^{2}$ Marine Science Faculty, The Highlands and Islands Millenium Institute, Oban PA34 4AD, United Kingdom \\ ${ }^{3}$ Scottish Association for Marine Science, Oban PA34 4AD, United Kingdom
}

\begin{abstract}
The vertical migration of Calanus finmarchicus and krill (Meganyctiphanes norvegica and Thysanoessa raschii) was monitored during the summer of 1999 in the Clyde Sea using a combination of acoustic and net sampling methods. A moored $300 \mathrm{kHz}$ acoustic Doppler current profiler (ADCP) identified a sound scattering layer (SSL) that started to ascend to the surface during the last moments of daylight. Net samples showed that the SSL was mostly composed of krill. C. finmarchicus rose to the surface in the late afternoon, causing a small but detectable increase in backscatter that did not vary in time through the summer. The ascent of krill, by contrast, became earlier as day length decreased towards autumn. Net samples showed that the strong downward Doppler velocities following the rise of the SSL was caused by the descent of $C$. finmarchicus. The fact that this coordinated sinking of C. finmarchicus occurred earlier towards autumn, even though the time of ascent to surface remained constant, implies that the feeding 'window' diminished over the course of the season. Feeding conditions did not become significantly better during this same period, discounting satiation as a likely cause of descent. The close temporal coupling between the arrival of krill and the subsequent descent of $C$. finmarchicus from the surface suggests that midnight sinking in Calanus is a response to predation.
\end{abstract}

KEY WORDS: Zooplankton · Copepod · Euphausiid · Vertical migration $\cdot$ Clyde Sea $\cdot$ ADCP

\section{INTRODUCTION}

Midnight sinking is 1 of the 5 phases of nocturnal vertical migration that is commonly performed by zooplankton (Cushing 1951). Several proximate causes for the behaviour have been put forward. Cushing (1951) believed it to be a passive response that results from the general slowing of swimming speed that occurs in complete darkness. Alternatively, Gauld (1953) and Pearre $(1973,1979)$ suggested that satiation was the cue for sinking, possibly operating through the slowing of swimming speed (e.g. Mackas \& Bohrer 1976) or the increase in density when satiated (e.g. Krause \& Radach 1989). The fact that midnight sinking takes place in complete darkness makes it unlikely that

*E-mail: gant@pcmail.nerc-bas.ac.uk visual predation has much influence, but tactile predation may play a role since motion has been shown to increase risk of predation in a number of studies (e.g. Wright \& O'Brien 1984, Torgersen 2001).

One of the biggest problems in determining the exact cause of midnight sinking is the fact that, in many instances, it is difficult to detect any sinking at all. Most studies rely on detecting differences in vertical distribution profiles over some course of time, either through depth-discrete net catch data (e.g. Wiebe et al. 1992) or through acoustic sound scattering layers (SSLs) (e.g. Boden \& Kampa 1967). This can only assess degree of mass transfer between depth levels, potentially integrating both the upward and downward movements of many individuals. Other studies have used tracers as indirect evidence of zooplankton movement otherwise missed by conventional sampling 
methods. This works on the principle that animals found in one depth layer contain food particles that could have only been obtained from another depth layer, proving that they must have migrated vertically at some point.

The acoustic Doppler current profiler (ADCP) is a recent technological advance that is able to obtain extra behavioural information that improves our insight into vertical migration behaviour. The instrument was designed to determine the velocity and direction of currents through the water column, but can also measure the vertical distribution and quantity of zooplankton biomass in the water column, as shown by Greenlaw (1979). The advantage of the ADCP over conventional echo sounders is its capability to estimate the velocity of zooplankton in the vertical plane through measuring Doppler shift (Pleuddeman \& Pinkel 1989). Analysis of this parameter overcomes some of the problems of traditional methods because it measures the average swimming behaviour of individuals rather than the bulk movements of populations.

This study uses a $300 \mathrm{kHz}$ ADCP over a continuous period in the summer of 1999 in the Clyde Sea to investigate the vertical migration behaviour of zooplankton species, in particular the copepod Calanus finmarchicus and the krill species Meganyctiphanes norvegica and Thysanoessa raschii. C. finmarchicus is particularly widespread throughout most of the North Atlantic basin and peripheral shelf seas, and is capable of migrating over several hundred meters (Longhurst \& Williams 1979) and of attaining vertical velocities approaching $0.01 \mathrm{~m} \mathrm{~s}^{-1}$ (Hardy \& Bainbridge 1954). Observations of midnight sinking behaviour in this species are common (e.g. Gauld 1953, Simard et al. 1985, Durbin et al. 1995). The species is primarily herbivorous and relatively flexible in adapting its feeding rhythms to environmental conditions (Daro 1988). It passes through between 1 and 3 generations $\mathrm{yr}^{-1}$, according to location, during which the majority of stages occupy vertical layers above $50 \mathrm{~m}$. However, approaching winter, a large percentage of the population remains at a sub-adult stage (Copepodid V) and enters a state of diapause. This stage may stop performing diel vertical migration and remain in the deeper layers until the following spring. C. helgolandicus sometimes occurs in the Clyde Sea and exhibits a similar biology. Thysanoessa raschii and Meganyctiphanes norvegica are two of the most abundant krill species in the North Atlantic basin. Their distributional ranges are quite extensive, stretching from the European shelf, across the North Atlantic basin into the Arctic water masses of the north-west (Dalpadado et al. 1998). Within this range, T. raschii is principally a neritic species and $M$. norvegica an inhabitant of both on- and off-shelf regions (especially shelf breaks). Both $M$. norvegica and T. raschii are strong vertical migrators (Mauchline 1966) and both exhibit midnight sinking behaviour (Simard et al. 1986, Tarling et al. 1999). M. norvegica is omnivorous (Lass et al. 2001) and is an effective predator on C. finmarchicus, especially the earlier copepodid stages (Båmstedt \& Karlson 1998). T. raschii is more herbivorous by comparison (Sameoto 1980), but crustacean remains have been found in its stomach contents (Mauchline 1966).

The approach of this study is to examine the vertical migration of each of these 3 species continuously over a 3 mo time period using a moored ADCP. The data are analysed with respect to the vertical velocity of individuals as well as the bulk movements of populations, with comparisons to accompanying net samples in order to determine the species that are responsible for the acoustic patterns. Irradiance data are used to investigate how seasonal changes in day length affect migration patterns. Ultimately, the study addresses the hypothesis that krill, as predators, influence the vertical migration patterns of Calanus finmarchicus more than any satiation-induced effect or signal.

\section{MATERIALS AND METHODS}

Field sampling. All sampling was carried out within a trench region of the Clyde Sea, stretching from the Arran Deep $\left(55.65^{\circ} \mathrm{N}, 5.10^{\circ} \mathrm{W}\right)$ to Inchmarnock Water $\left(55.80^{\circ} \mathrm{N}, 5.20^{\circ} \mathrm{W}\right)$ (Fig. 1). Water depth within the trench ranged between 140 and $160 \mathrm{~m}$. The Grand Plateau ( $<50 \mathrm{~m}$ deep) separates this trench from the open water of the Irish Sea and North Channel to the south-west. Another deep-water trench region in Loch Fyne, to the north-west, is separated from the Clyde Sea area trench by a series of shallow sills.

A U-shaped mooring was placed at Inchmarnock Water for the periods from 24 June to 13 August 1999 and 16 August to 4 October 1999. The mooring supported a $300 \mathrm{kHz}$ Workhorse (Broadband) ADCP at $110 \mathrm{~m}$ depth in upward looking mode and a fluorometer at $2 \mathrm{~m}$. The ADCP was set to collect 15 depth 'bins' of $8 \mathrm{~m}$ depth and to ping at a frequency of 12 per $2 \mathrm{~min}$ averaging interval. The resulting standard deviation of velocity measurements was $0.6 \mathrm{~cm} \mathrm{~s}^{-1}$. Data were collected continuously for the entire duration of both deployment periods. The fluorometer sampled every $2 \mathrm{~h}$ and collected data during the second deployment (August to October) only. A LI-COR 200SA pyranometer was placed on an unobstructed rooftop in Tarbert, approximately $20 \mathrm{~km}$ away from the site of the mooring, to measure global solar radiation (sun plus sky). It was operated continuously from 31 June to 4 October, recording data averaged over 1 min intervals. 


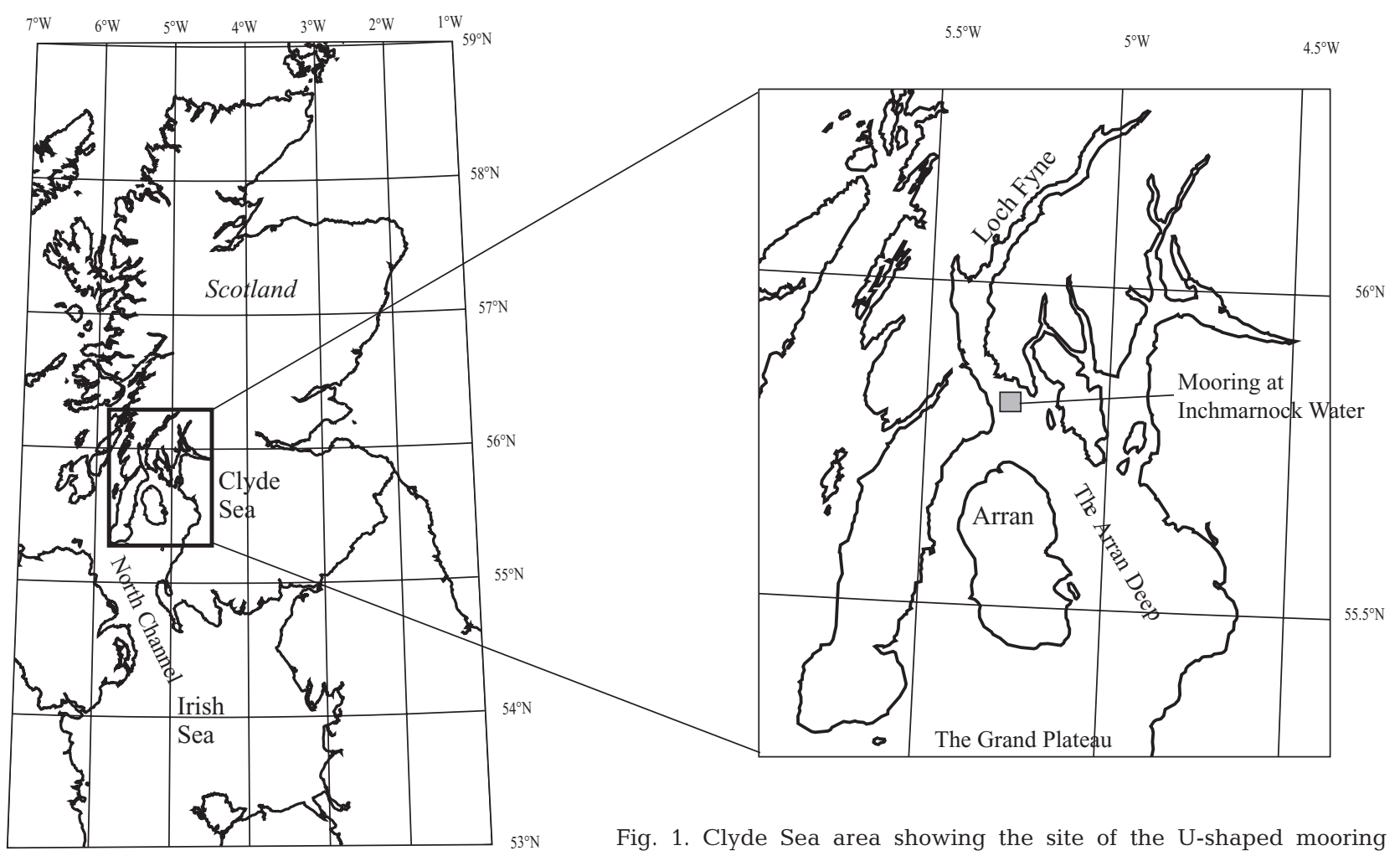

The first net sampling campaign was carried out between 28 June and 2 July on board RV 'Calanus', a $25 \mathrm{~m}$ vessel equipped with an $11 \mathrm{~mm}$ conducting cable winch. Numerous visits to the vicinity of the U-shaped mooring were timetabled such that, by the end of the $5 \mathrm{~d}$ period, samples were taken at all phases of the day/night cycle. This approach was necessary because the ship was not capable of spending more than $12 \mathrm{~h}$ $\mathrm{d}^{-1}$ at sea. The ship's winch was used to operate a $1 \mathrm{~m}^{2}$ multiple open/closing net system (MOCNESS; BESS Dartmouth; see Wiebe et al. 1985), fitted with up to 9 nets with a mesh size of either 330 or $2000 \mu \mathrm{m}$, a flowmeter, and SeaBird temperature and conductivity sensors. The net operates through commands sent along a conducting cable via a LAN system, and an on-board PC 13 MOCNESS deployments, each lasting $30 \mathrm{~min}$, were made over the course of the campaign to sample Calanus and krill. Net 1, with a $330 \mu \mathrm{m}$ mesh, was open during the descent of the net to within $15 \mathrm{~m}$ of bottom. The other nets, with a $2000 \mu \mathrm{m}$ mesh, were opened sequentially while the net was being hauled in, so that the water column was sampled in 6 discrete intervals of $\leq 30 \mathrm{~m}$. The net was lowered at $0.5 \mathrm{~m} \mathrm{~s}^{-1}$ and raised at $0.2 \mathrm{~m} \mathrm{~s}^{-1}$, and the towing speed was 2.5 knots. Two further hauls were made to study the vertical distribution of copepods and other mesozooplankton, one around midday (09:55 h), the other close to midnight $(23: 50 \mathrm{~h})$. Times are given in UTC, which is British summer time (BST) minus $1 \mathrm{~h}$. The net system was equipped entirely with $330 \mu \mathrm{m}$ mesh nets for both deployments. All samples were fixed in 10\% formalin and subsequently preserved in alcohol. A SeaBird conductivity temperature depth recorder (CTD) was used during periods when the net was not in operation. Surface water samples $(2 \mathrm{~m})$ were taken around midday and analysed by fluorometry according to HolmHansen et al. (1965).

The second sampling campaign was carried out on board RV 'Calanus' between 10 and 16 August 1999. A failure in the conducting cable prevented communication with the MOCNESS and disabled any depthdiscrete sampling capability. Nevertheless, the net was used to obtain depth-integrated samples by means of double-oblique tows. The MOCNESS was customised by fixing a horizontal bar half-way along the net mouth and securing a $330 \mu \mathrm{m}$ mesh net to the upper half and a $2000 \mu \mathrm{m}$ mesh net to the lower half; thus, allowing krill and mesozooplankton to be fished simultaneously. Three tows were made in quick succession, the first paying out $50 \mathrm{~m}$ of wire, the second $100 \mathrm{~m}$ and the third $150 \mathrm{~m}$. Ship speed was 2.5 knots. Subsequent calibration hauls, carried out at the same ship speed and with a depth/time recorder (VEMCO TDX) attached to the MOCNESS frame, estimated the maximum depth of these hauls to be 20,40 and $60 \mathrm{~m}$, respectively. This 3 haul deployment protocol was carried out a total of 4 times during the campaign, within daytime, dusk and early night-time periods. 
Depth-discrete net samples, to determine the vertical distribution of mesozooplankton, were obtained with an open/closing WP2 net (diameter $1 \mathrm{~m}$, mesh size $500 \mu \mathrm{m})$. The net was deployed vertically and opened and closed via a manual trigger mechanism and messengers. The water column was sampled in 20 to $30 \mathrm{~m}$ intervals from $130 \mathrm{~m}$ to the surface between 21:03 and 21:30 h on 10 August and between 11:05 and 11:36 h on 11 August. All samples were fixed in $10 \%$ formalin and subsequently preserved in alcohol. CTD profiles were taken as for the previous campaign. Water samples for fluorometric analysis were taken during the retrieval of the mooring (4 and 6 October).

Home laboratory zooplankton analysis. The Clyde Sea area contains 2 krill species, Meganyctiphanes norvegica and Thysanoessa raschii (Mauchline 1960). These species were separated and counted. Mesozooplankton was sub-sampled using a combination of a Folsom splitter, a Stempel pipette and a Bogorov tray. Identification and enumeration were carried out under a binocular microscope (Olympus SZX 9 with $10 \times$ magnification eye pieces). In the case of Calanus finmarchicus, additional sub-sampling was carried out to ensure that at least 100 specimens were identified and staged in every sample.

Satellite data. A time-series of chlorophyll a ( $\mathrm{chl} \mathrm{a}$ ) concentrations were derived from the sea-viewing wide field-of-view sensor (SeaWiFS) ocean colour satellite. Values were taken from nine $4.4 \mathrm{~km}$ pixels in the vicinity of the mooring in Inchmarnock Water $\left(55.75\right.$ to $50.85^{\circ} \mathrm{N}, 5.20$ to $5.30^{\circ} \mathrm{W}$ ) and were integrated into $6 \mathrm{~d}$ averages between 25 June and 3 October, 1999. The values were converted to chl a biomass (mg $\mathrm{m}^{-3}$ ) using the 'bright pixel' atmospheric correction algorithm developed by the Plymouth Marine Laboratory (Moore et al. 1999) and the NASA OC2V2 chlorophyll algorithm (O'Reilly et al. 1998).

Acoustic data. The echo intensity data collected by the $300 \mathrm{kHz}$ Broadband WH-ADCP was converted to Sv (backscattering strength in decibels [dB]) following the methods outlined by Deines (1999). The method involved replacing certain combinations of terms in a working version of the sonar equation by quantities that were either measured at the factory or available from the data records of the instrument.

Table 1. Estimates of chlorophyll a (SD in brackets) in Inchmarnock Water in late June, late July and late August 1999

\begin{tabular}{|cccccc|}
\hline \multirow{2}{*}{$\begin{array}{c}\text { Chl } a \\
\left(\mathrm{mg} \mathrm{m}^{-3}\right)\end{array}$} & \multicolumn{2}{c}{ SeaWiFS } & Bottle samples & Late July & \multicolumn{2}{c|}{$\begin{array}{c}\text { Late August } \\
\text { SeaWiFS }\end{array}$} & SeaWiFS Fluorometer \\
\hline $0.35(0.77)$ & $0.83(0.44)$ & $2.21(1.55)$ & $1.81(2.53)$ & $1.79(0.67)$ \\
\hline
\end{tabular}

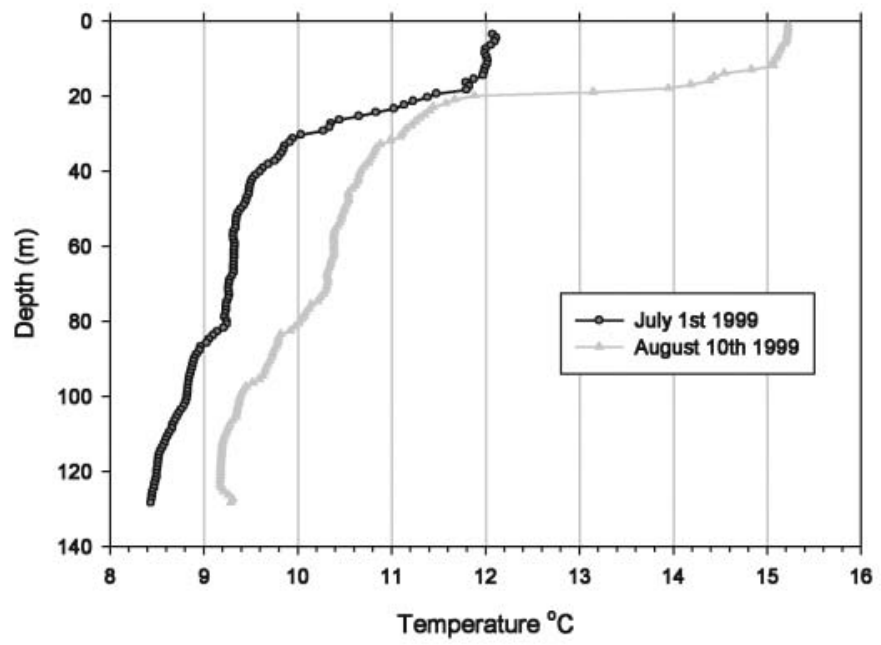

Fig. 2. Temperature profiles of the Clyde Sea area on 1 July (dark circles) and 10 August 1999 (light triangles)

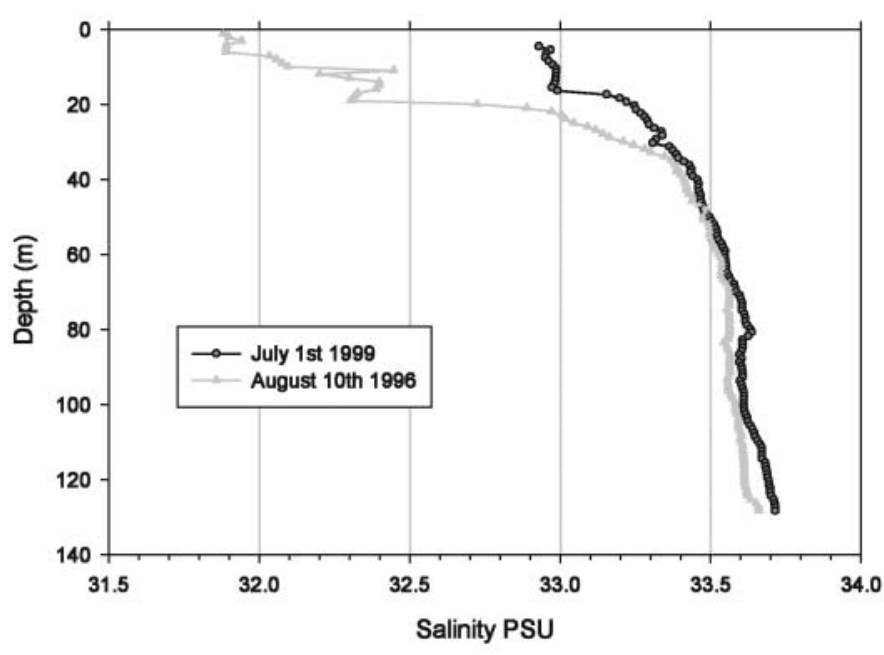

Fig. 3. Salinity profiles of the Clyde Sea area on 1 July (dark circles) and 10 August 1999 (light triangles)

The Doppler vertical velocity data showed a bias towards downward movement when values were averaged over all depths. This bias was deducted from the data to give the 'Doppler vertical velocity anomaly', which is a better representation of the actual upward and downward migrations of the scatterers.

In the case of both $\mathrm{Sv}$ and Doppler vertical velocity, $6 \mathrm{~d}$ of continuous data were synthesised to give a 'model day' in late June, late July and late August 1999. The synthesised periods were: 25 June to 1 July; 24 to 30 July; and 23 to 29 August, respectively. 
Fig. 4. Absolute backscatter (dB) averaged over: (A) 25 June to 1 July; (B) 24 to 30 July; (C) 23 to 29 August 1999
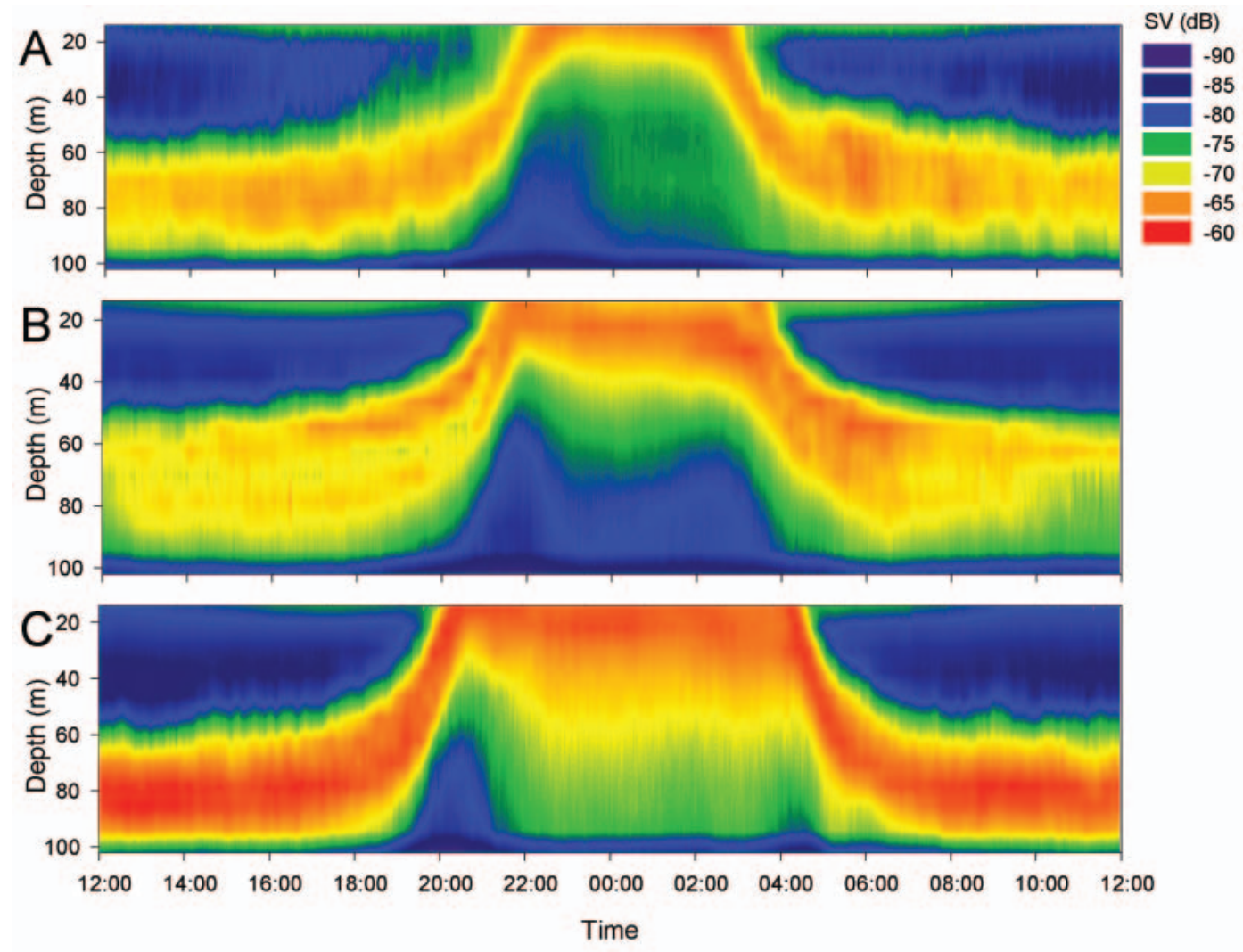

\section{RESULTS}

\section{Environmental data}

A distinct thermocline was present at the start of July and the middle of August (Fig. 2). On 1 July, the thermocline was almost $20 \mathrm{~m}$ deep but had risen $5 \mathrm{~m}$ by 10 August. The whole water column had also warmed by over $3^{\circ} \mathrm{C}$ in the surface mixed layer and by around $1^{\circ} \mathrm{C}$ near the bottom. A drop in the salinity of the surface mixed layer between July and August (Fig. 3) was probably the result of greater freshwater run-off later in the season.

Chl a levels estimates by SeaWiFS did not differ significantly at the $\mathrm{p}<0.05$ level from the water bottle samples in late June or the fluorometer data in late $\mathrm{Au}-$ gust (Mann-Whitney rank sum test; Table 1). Levels of chl a biomass $\left(\mathrm{mg} \mathrm{m}^{-3}\right)$ were the same order of magnitude in late June, late July and late August although levels in late July were significantly higher $\left(2.21 \mathrm{mg} \mathrm{m}^{-3}\right.$; Kruskall-Wallis 1-way ANOVA) than in late June $\left(0.35 \mathrm{mg} \mathrm{m}^{-3}\right)$. Chl a biomass fell in late August to a level that was between those present in late June and late July.

\section{Acoustic data}

The 'model day' Sv plots extracted from the moored $300 \mathrm{kHz}$ ADCP in June, July and August 1999 are shown in Fig. 4A,B,C respectively. The lower limit to the profiles is set by: (1) the depth of the instrument $(110 \mathrm{~m})$; and (2) the acoustic blanking region, which is the region next to the ADCP in which data cannot be collected because of the ringing of the transducer after the end of the transmit pulse. The upper limit does not extend to the surface as a result of: (1) part of the final bin being above the sea surface; and (2) the penultimate bin being influenced by surface reflection. In all plots, there was a distinct SSL between 60 and $100 \mathrm{~m}$ during the daytime, which showed a characteristic pattern of diel vertical migration. Sv values within the SSL ranged between -65 and $-70 \mathrm{~dB}$ in both June and July, and reached up to $-60 \mathrm{~dB}$ in August. A trend was apparent within the patterns of migration, proceeding from June to August, with upward migration becoming earlier and downward migration becoming later. There was a dramatic drop in the Sv level in the lower part of the water column following the upward movement of the SSL during dusk. The Sv levels in the deep then recovered as the SSL dispersed from the upper to lower layers.

Fig. 5 shows corresponding Doppler vertical velocity anomaly data. In all plots, the water column can be divided into 2 layers during the daytime. In the upper layer, there was a general upward movement whereas, in the lower layer, downward movement was evident. As dusk approached, there was a 30 to 60 min period of 

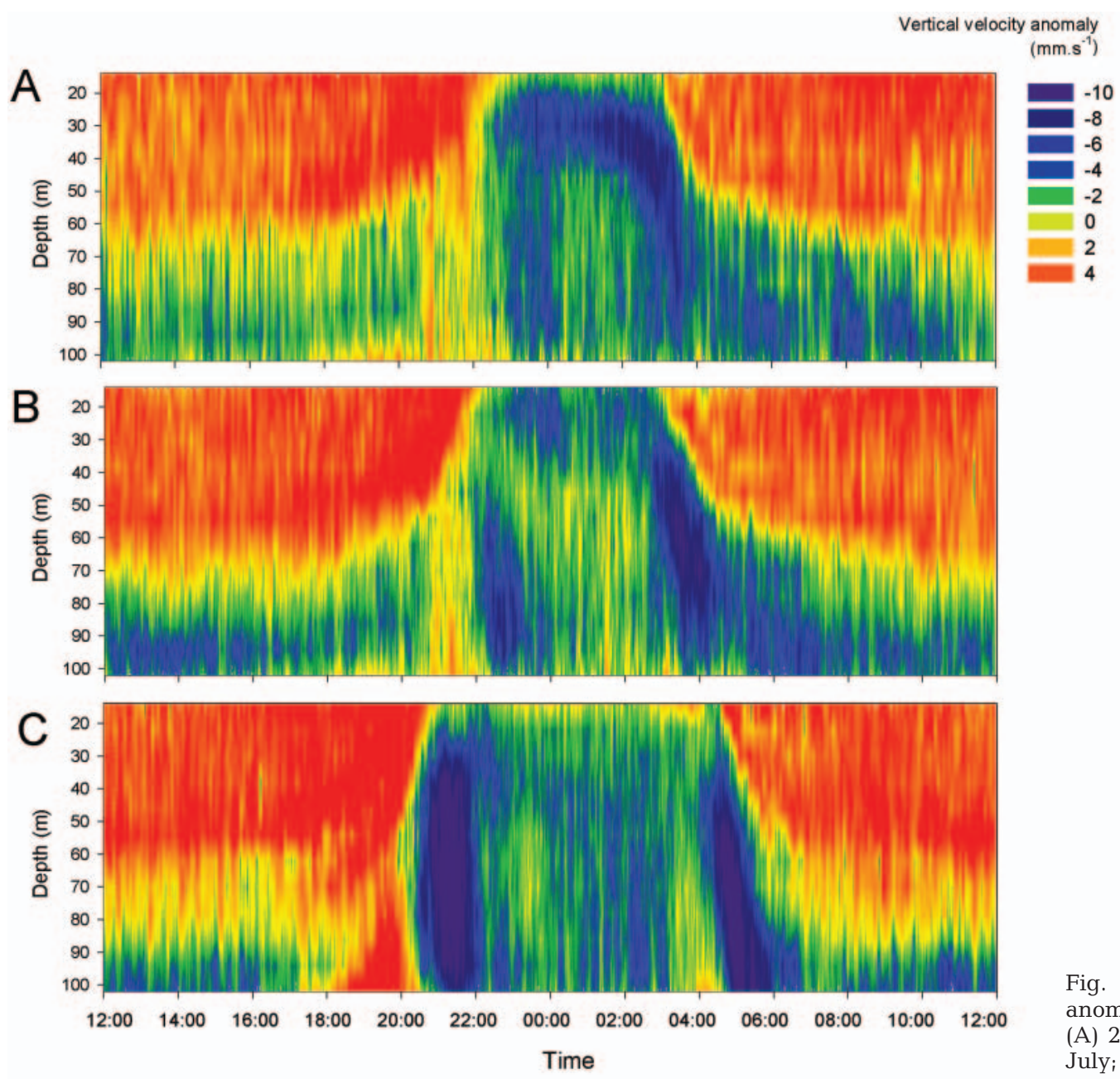

Fig. 5. Doppler vertical velocity anomaly ( $\mathrm{mm} \mathrm{s}^{-1}$ ) averaged over: (A) 25 June to 1 July; (B) 24 to 30 July; (C) 23 to 29 August 1999

upward velocities, reaching up to $4 \mathrm{~mm} \mathrm{~s}^{-1}$, although by night-time, downward velocities were found through almost the whole water column. The night-time was marked by 2 periods of intense downward velocity movements, the first period occurring post-dusk, immediately after the upward velocity phase had ended, and the second period pre-dawn. The post-dusk movement occurred between 22:00 and 00:00 h in June but was almost $2 \mathrm{~h}$ earlier by August (20:00 to 22:00 h). The movement also became more distinctive and intense proceeding through the season, with maximum downward velocity anomalies being around $6 \mathrm{~mm} \mathrm{~s}^{-1}$ in June but as high as $10 \mathrm{~mm} \mathrm{~s}^{-1}$ in August. Neither of the downward velocity movements corresponded to the location of the SSL. During the post-dusk downward movement, the SSL was close to the surface and there was only a small increase in Sv in the lower part of the water column, mainly after the most intense period of downward velocity was finished. Similarly, during the pre-dawn downward movement, the migration of the main part of the SSL downwards (signified by the close contours) occurred approximately $30 \mathrm{~min}$ after the downward movement had ended.
Fig. 6 compares absolute light levels (I) and relative rate of change $(\Delta \mathrm{I} / \mathrm{I})$ to backscatter at the surface and the depth-averaged Doppler vertical velocity anomaly. Two peaks were evident in the relative rate of change, firstly, as light decayed towards dusk and, secondly, as it increased at dawn. The peak rate of change occurred when the absolute light level was less than $1 \mathrm{~W} \mathrm{~m}^{-2}$ during both the dusk and dawn periods. Proceeding from June to August, these peaks became progressively earlier at dusk and progressively later at dawn, in line with the annual solar cycle. In terms of backscatter, a moderate peak was noticeable around 17:00 h in June, July and August, which was followed by a small dip and then a more dramatic increase later in the evening, when the SSL arrived (see Fig. 4). Whereas the timing of the first moderate peak did not change from 17:00 $\mathrm{h}$ between months, the arrival of the SSL became progressively earlier from June to August. In all months, the first arrival of the SSL consistently occurred when the relative rate of change was $0.05 \mathrm{~min}^{-1}$; the absolute light level at this moment varied from less than $5 \mathrm{~W} \mathrm{~m}^{-2}$ in June to more than $10 \mathrm{~W} \mathrm{~m}^{-2}$ in August. The results suggest that the relative rate of change of light 


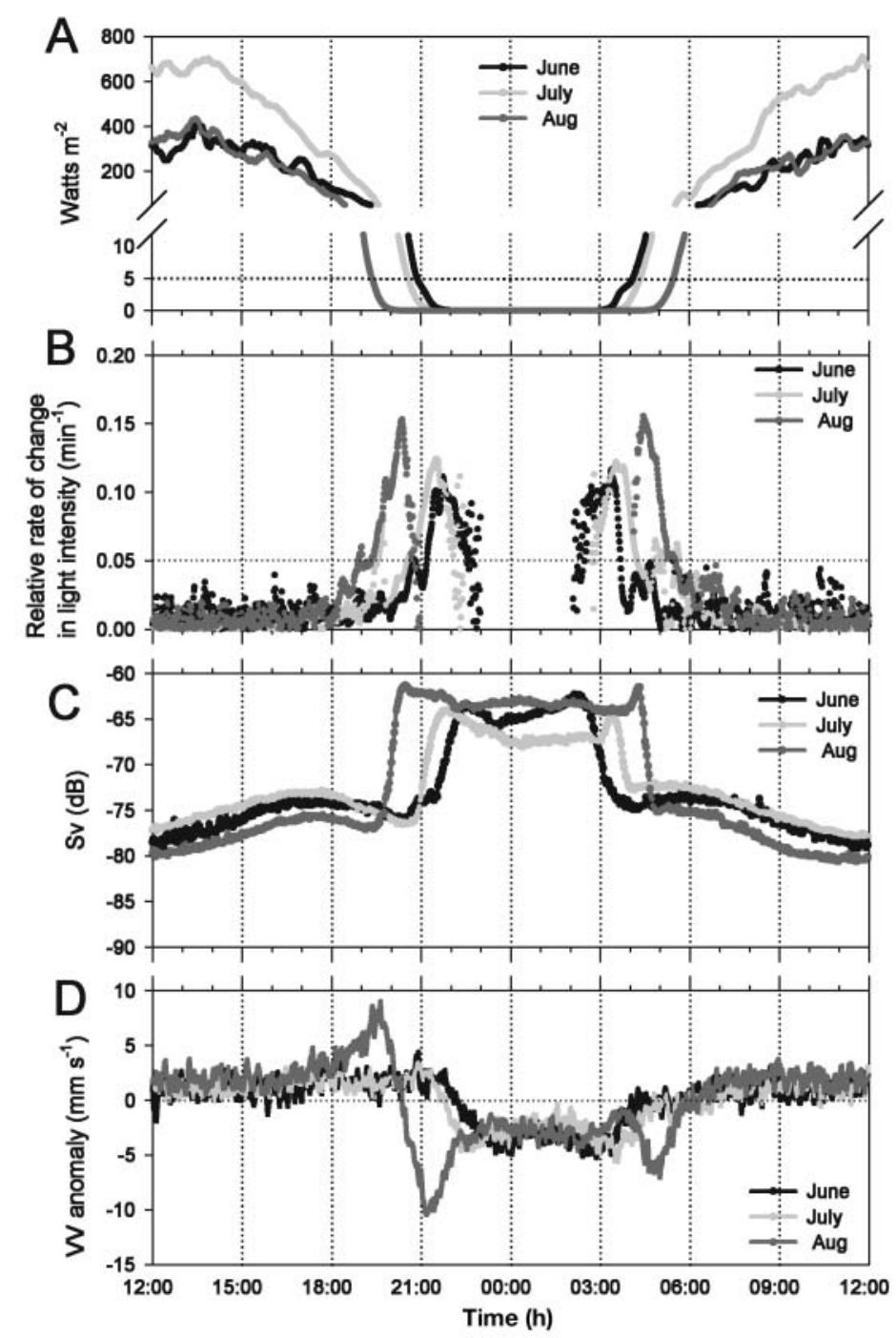

Fig. 6. (A) Solar irradiance (sun plus sky; $\mathrm{W} \mathrm{m}^{-2}$ ); (B) relative rate of change in light intensity $\left(\Delta \mathrm{I} / \mathrm{I}_{i} \mathrm{~min}^{-1}\right)_{;}(\mathrm{C})$ absolute backscatter $(\mathrm{dB})$ in the upper depth strata $(18$ to $10 \mathrm{~m})$; (D) depth integrated (106 to $10 \mathrm{~m}$ ) vertical velocity anomaly $\left(\mathrm{mm} \mathrm{s}^{-1}\right)$. All data are averaged over the periods from 25 June to 1 July, 24 to 30 July and 23 to 29 August 1999

was more important as a co-ordinator of vertical migration than the absolute light level. The accompanying Doppler vertical velocity anomalies (Fig. 6D) showed a moderate positive (upward) peak during the late evening, when the SSL moved to the surface. This was followed immediately by a downward trend in Doppler vertical velocity, which reached its most negative point around $30 \mathrm{~min}$ after the backscatter at the surface had reached its peak. Doppler velocity values became less negative for the rest of the night until a second negative dip occurred just before dawn. Depth integrated Doppler velocities rose to daytime levels after the period of downward migration had ended.

Fig. 7 gives a daily perspective on the correspondence between the acoustic patterns and light levels.
The time that the SSL first arrived at the surface and the subsequent downward shift in Doppler velocities followed the seasonal decay in day length. The first arrival of the SSL occurred just before light became extinct each day, when the relative rate of change in light was increasing rapidly. According to Figs. 5 \& 7, backscatter continued to increase in the surface layer after this point until a peak was reached approximately $1 \mathrm{~h}$ later. Strong downward Doppler velocities were recorded after this point. This means that the strong downward velocities always occurred between 30 and 60 min after the main core of the SSL arrived at the surface.

\section{Net-catch data}

Fig. 8 presents the vertical distributions of the most common mesozooplankton caught during the day and night in the 2 net sampling campaigns. The composition of the mesozooplankton community remained relatively constant between the periods of study. Acartia clausi, Pseudocalanus sp. and Paracalanus parvus numerically dominated the community in each period. Cladocerans Evadne and Podon were also relatively numerous, as was Centropages spp., and the eggs of fish and euphausiids. Euphausiid calyptopes and furciliae and decapod larvae made up a significant part of the zooplankton community in August but were absent in July. Compared with July, almost all taxa in August had deeper daytime distributions and the vertical migrations performed by taxa such as Pseudocalanus, Paracalanus and the cladocerans spanned greater depth ranges.

Fig. 9 shows that Calanus finmarchicus was relatively well spread through the water column both day and night during the 2 sampling campaigns, particularly in the later developmental stages. In July

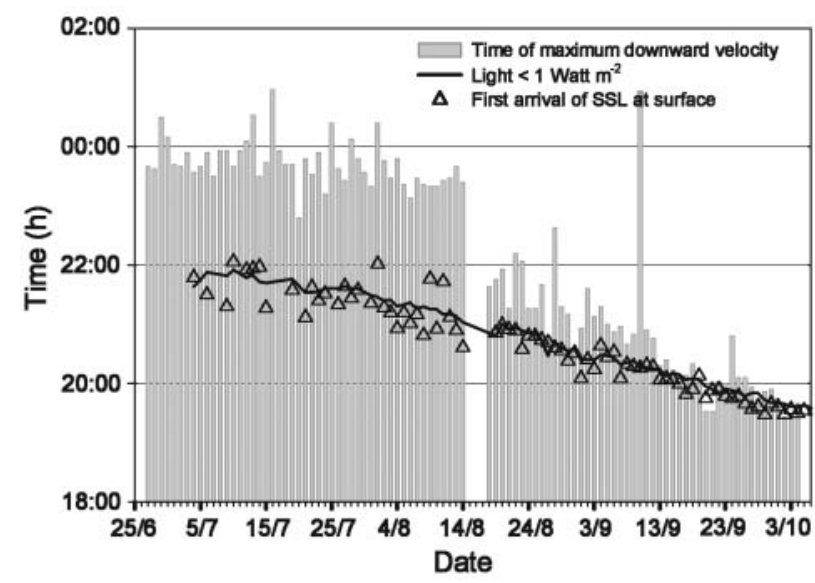

Fig. 7. Time of maximum downward velocity (grey bars), last recorded light (black line) and first arrival of the sound scattering layer (SSL) in the surface layer (open triangles) from 29 June to 3 October 1999 


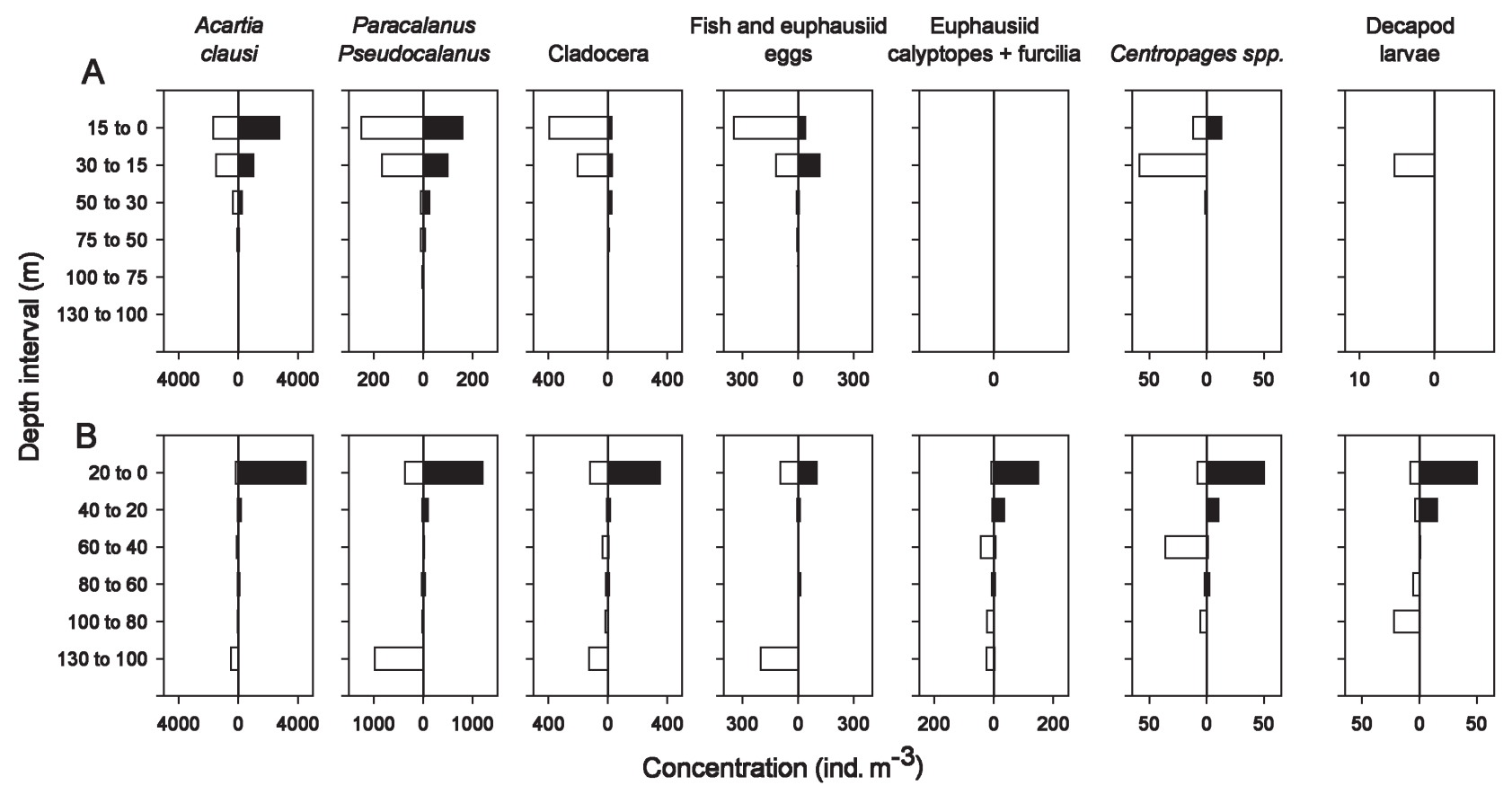

Fig. 8. Depth distribution of the 7 most abundant mesozooplankton taxa in (A) 28 June to 2 July 1999 and (B) 10 to 16 August 1999. White bars: around midday; black bars: around midnight

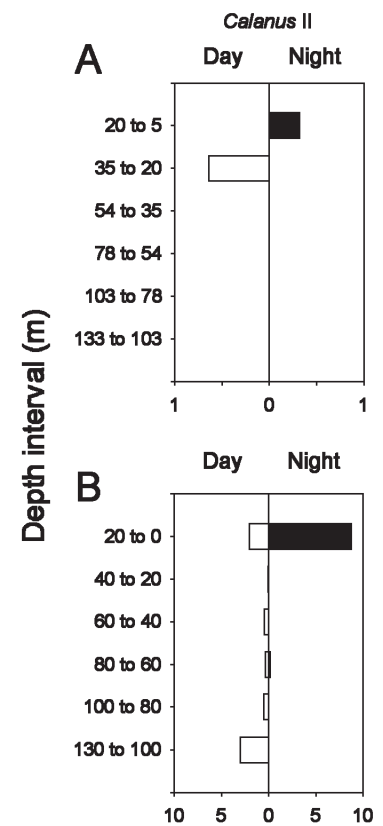

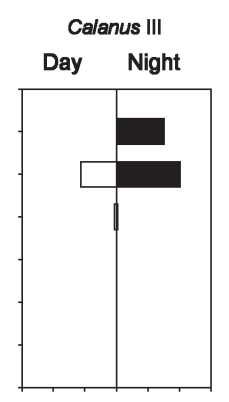
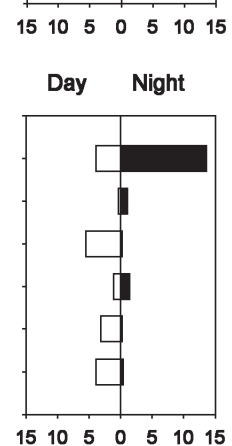
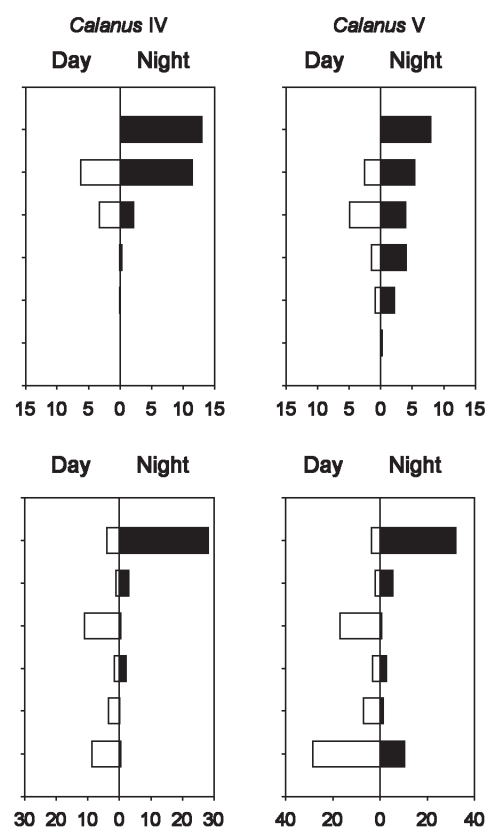

Concentration (ind. $\mathrm{m}^{-3}$ )
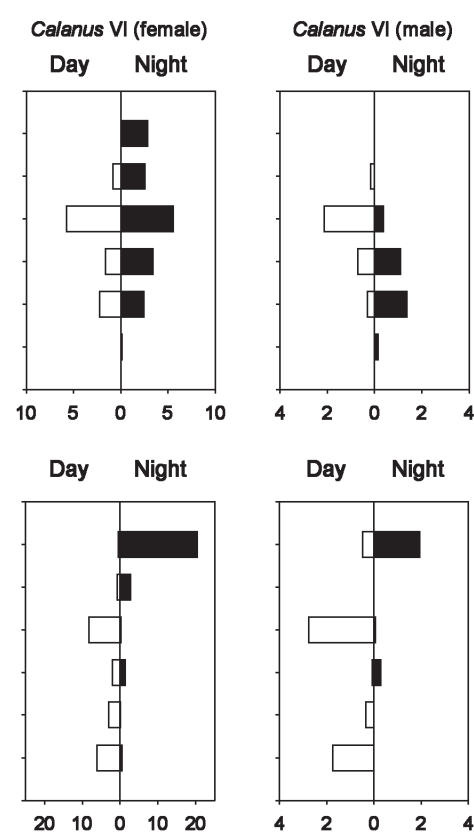

Fig. 9. Calanus finmarchicus. Depth distribution of developmental stages during daytime (white bars) and nighttime (black bars). (A) 1-2 July 1999; (B) 10-11 August 1999

(Fig. 10A,B), more advanced developmental stages occurred at increasingly greater depths. The earlier stages (III to IV) spread over a 40 to $60 \mathrm{~m}$ depth range and moved from a modal depth of between 20 and
$40 \mathrm{~m}$ during the day to the surface during the night. Stage V and adult females had a much wider depth distribution both day and night and, although more individuals tended to concentrate near the surface at 


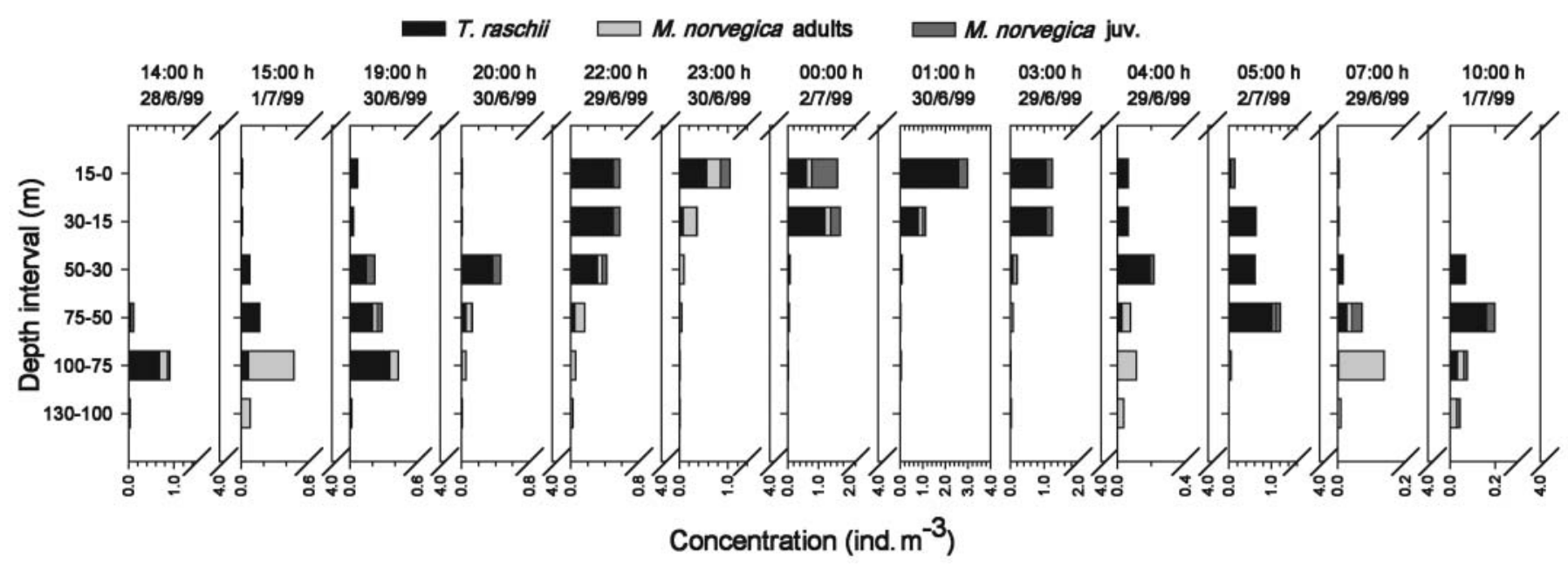

Fig. 10. Thysanoessa raschii, and Meganyctiphanes norvegica adults and juveniles. Depth distribution over a diel cycle averaged between 28 June and 2 July 1999

night, there were still a significant number of individuals present at almost all other depths at that time. In August, the concentration of individuals in all developmental stages was considerably higher than in the previous campaign. The significant number of early developmental stages indicates that the population was still breeding. These early developmental stages underwent a much more extensive vertical migration than in July since they occurred at much greater depths during the daytime. The daytime distribution was bimodal, with one modal depth between 60 and $40 \mathrm{~m}$ and another between 130 and $100 \mathrm{~m}$. This pattern was also apparent in the Stage $\mathrm{V}$ and adult female depth distributions. All developmental stages concentrated at the surface during the night. Stage V differed from the other stages by the fact that individuals were also found in relatively large numbers in the deep $(100$ to $130 \mathrm{~m})$ during the night. Adult males did not make up a significant part of the population in any of the campaigns.

The extensive series of MOCNESS deployments with $2000 \mu \mathrm{m}$ mesh nets in late June allowed detailed temporal insights into the diel vertical migration of krill. A classical diel vertical migration pattern was apparent in both Thysanoessa raschii and Meganyctiphanes norvegica (Fig. 10), with a movement from deep to surface layers around dusk $(20: 00 \mathrm{~h})$ and a return to deep layers around dawn (04:00 h). This vertical migration involved almost the whole euphausiid community, since there were very few individuals left at the surface during the day and virtually no individuals below $60 \mathrm{~m}$ during the night. Both T. raschii and $M$. norvegica adults were principally located within the 75 to $100 \mathrm{~m}$ depth-interval during the day, although juveniles were more common in the 50 to $75 \mathrm{~m}$ depth interval.
In August, further MOCNESS hauls, using $330 \mu \mathrm{m}$ mesh nets, were taken between 0 and $20 \mathrm{~m}$ regularly during the day and early night to give an insight into the relative times of arrival of Calanus finmarchicus and krill in the surface layers (Fig. 11). Both the CIII/CIV and the CV/CVI stages of C. finmarchicus arrived in the surface layers in large numbers between the middle of the morning $(09: 00 \mathrm{~h})$ and late afternoon $(18: 00 \mathrm{~h})$, reaching combined concentrations in excess of 100 ind $\mathrm{m}^{-3}$. Concentrations of all stages subsequently decreased by 20:00 $\mathrm{h}$ and continued to fall until reaching levels at $02: 00 \mathrm{~h}$ that were similar to those observed in the daytime. Unlike $C$. finmarchicus, krill were absent from the surface layers until much later in the evening (20:00 h). Once they had arrived however, their level of concentration in this stratum remained similar through the course of the night.

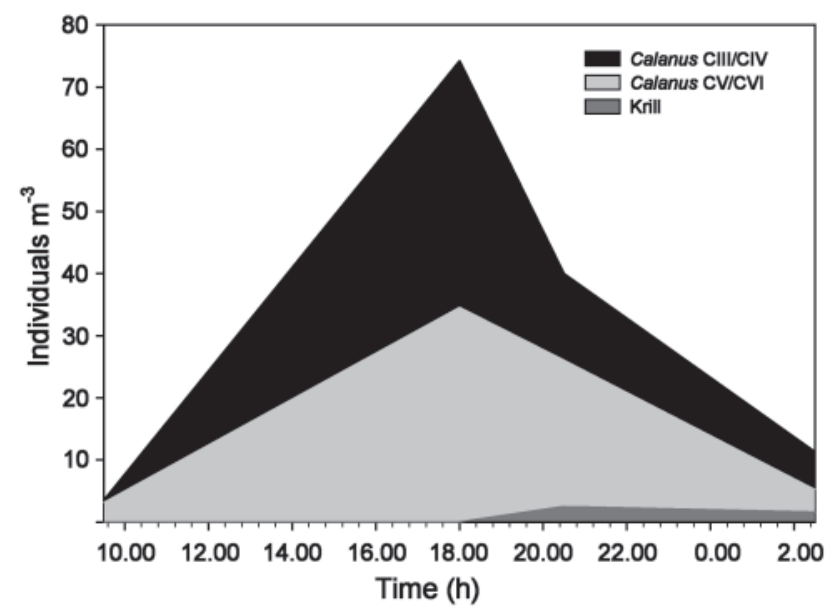

Fig. 11. Calanus finmarchicus CIII-CIV, CV-CVI, and krill. Concentrations between 0 and $20 \mathrm{~m}$ during the day and early night 


\section{DISCUSSION}

The comparison of net catches with the ADCP data shows that different taxa are responsible for different acoustic patterns. The depth distribution of the krill community sampled by the nets matches well with the location of the SSL both during the day- and night-time phases. The time resolution of the mesozooplankton net catches was limited by comparison with those carried out for krill. Nevertheless, many taxa can be eliminated from being potential contributors to the SSL by the fact that they were distributed in the upper layers during daytime where the level of backscatter was low. The contribution of Calanus finmarchicus to the SSL is less clear. The distributions of younger developmental stages were between 60 and $20 \mathrm{~m}$ during the day, which would discount them from being part of the SSL. However, CV and adult stages were located 20 to $40 \mathrm{~m}$ deeper, which places them within the SSL, making them potential contributors. Evidence that the older stages of $C$. finmarchicus can make a contribution to $\mathrm{Sv}$ levels is seen in the comparison of August net catches (Fig. 11) to Sv levels (Fig. 6) in the late afternoon. The net catches revealed that $C$. finmarchicus numbers at the surface increased dramatically between 17:00 and 18:00 h, whilst backscatter increased at the surface by around $5 \mathrm{~dB}$ around this period. Krill were found only in the deeper layers. Nevertheless, this increase was small by comparison to the jump of $15 \mathrm{~dB}$ that occurred when the SSL arrived later on in the evening. It can be concluded that the older Calanus stages were the smallest crustaceans to be detected by the $300 \mathrm{kHz}$ ADCP but their contribution to Sv levels was small compared with that of krill.

Identifying Calanus as being the principal cause of the strong downward Doppler velocities observed after dusk is based on the fact that net samples taken in the region of the band contained much higher concentrations of Calanus than of krill. Although it remains possible that krill contributed to the downward velocity signal, the nature of the Doppler velocity measurement makes this unlikely. The Doppler velocity value for a depth/time bin is an average of the movements of all detected particles (Pleuddemann \& Pinkel 1989). This means that the speed of a scatterer migrating through a depth/time bin will be biased low by the non-migrating scatterers also within that bin. Calanus outnumbered krill in the vicinity of the downward velocity band by approximately 25:1, meaning that, if Calanus were stationary and only krill were moving, krill must swim downwards at a speed in excess of $250 \mathrm{~mm} \mathrm{~s}^{-1}$ to make the overall average $10 \mathrm{~mm} \mathrm{~s}^{-1}$ (i.e. the speed of the downward velocity event). Undoubtedly other scatterers will also contribute to the 'quasi-stationary' background, making the required swimming speed even higher. Although
Tarling et al. (2001) registered krill downward velocities in the order of $110 \mathrm{~mm} \mathrm{~s}^{-1}$, higher speeds are unlikely on both physiological and biomechanical grounds (Kils 1981). Calanus is a slower swimmer than krill, but if the population migrated downwards in synchrony, their much larger abundance would make the event more conspicuous in the Doppler velocity records than would a smaller number of higher speed migrators. Calanus is therefore the most likely cause of the Doppler downward velocities recorded after dusk.

There were marked trends in the biological patterns evident in the ADCP data over the course of the summer. The first arrival of the SSL coincided with the rapid relative rate of change in light $(\Delta \mathrm{I} / \mathrm{I})$, just before its extinction, each day over the study period (Fig. 7). This close correspondence during the upward migration of the SSL agrees with Ringelberg (1995), who considered that $\Delta \mathrm{I} / \mathrm{I}$ was the primary causal factor evoking upward and downward migration. According to Ringelberg (1995), the presence of predators or variations in food concentration (called secondary causal factors) may enhance vertical migration, but cannot elicit migration. This would appear not to be the case in the present study since peak post-dusk downward velocity consistently occurred in complete darkness, 90 min after the first arrival of the SSL and approximately 40 min after $\mathrm{Sv}$ in the surface had reached its peak (Fig. 6). Fortier et al. (2001) made a similar finding on Calanus species in the Arctic, where individuals ascended into the chl a rich layer around the maximum $\Delta \mathrm{I} / \mathrm{I}$, but descended just a few hours later, well in advance of the dawn maximum $\Delta \mathrm{I} / \mathrm{I}$.

Measuring the speed of descent from the surface gives an idea of what type of swimming behaviour was being performed during midnight sinking. Doppler vertical velocities in both the post-dusk and pre-dawn downward phases were around $16 \mathrm{~mm} \mathrm{~s}^{-1}$. It is likely that the animals were travelling at an even higher speed given that Doppler measurements are biased low as a result of the quasi-stationary background (Pleuddemann \& Pinkel 1989). Passive sinking speeds of anaesthetised Calanus finmarchicus adults ranged between 1.5 and $8 \mathrm{~mm} \mathrm{~s}^{-1}$, depending on size (Gardiner 1933). This means that the Clyde Sea animals must have been actively swimming downwards during these phases. Therefore, this period of midnight sinking appears to be an avoidance mechanism rather than a period of disorientation and passive sinking, as first advocated by Michael (1911).

The fact that Calanus are actively avoiding krill is evidenced by the close temporal coupling between the arrival of krill and the subsequent descent of Calanus over the entire study period, despite the fact that the time of occurrence shifted by almost 4 h over this time (Fig. 7). Heywood (1996) made similar observations, 
finding that one SSL ascribed to copepods departed as soon as another SSL containing euphausiids arrived at the surface layer. Pinot \& Jansa (2001) identified a fast and a slow migrating band in the western Mediterranean, which were probably caused by Meganyctiphanes norvegica and copepods, respectively. They found that 2 bands arrived at the surface at different times, after which midnight sinking was observed.

The arrival time of Calanus in the surface layers, indicated by a small peak in backscatter (Fig. 6C), remained relatively unchanged over the study period $(17: 00 \mathrm{~h})$. In the most extreme case of June, this would be almost $5 \mathrm{~h}$ before the first arrival of the krill. It is estimated that gut filling time, although variable, is mostly in the region of 20 to $60 \mathrm{~min}$ (Wang \& Conover 1986). It is unlikely therefore that the mass movement of $C$. finmarchicus observed after the arrival of the SSL was mediated by gut fullness, since they would be replete well before this time. Gut fullness as a proximate or ultimate cue for midnight sinking is even more unlikely given that the time in the surface layers decreased by several hours between June and August. If the main reason for descent were satiation, one would expect the time of sinking to correspond to the level of food availability. The chl a data (Table 1) do not show a trend from which one would expect the period of time to gut satiation to drop exponentially between June and August, although it must also be considered that food quantity does not always correspond to food quality and ultimate feeding success. In any case, it is unlikely that, if gut fullness were the cause of sinking, it would correlate with day length so closely over the entire summer and yet be functionally independent of this parameter.

The observations suggest 2 alternative scenarios. In the first, after an initial movement to the surface around 17:00 h, there is a regular exchange of Calanus finmarchicus between the surface and deeper layers such that the distribution of biomass remains unchanged. Only when krill arrive do all C. finmarchicus, wherever they may be, respond by moving down together. In the second scenario, Calanus remain in the surface layers either continuing to feed or pausing between feeding bouts until the arrival of krill. In both scenarios, krill are the reason for the mass midnight sinking pattern. A number of other studies have observed midnight sinking in C. finmarchicus. Gauld (1953) noticed that animals in the deeper water of the Clyde Sea during the night contained food despite the fact that no obvious shift in biomass occurred. He hypothesised that the population was in a 'state of flux, some Calanus migrating upwards to feed and others downwards, out of the rich waters'. Simard et al. (1985) found that a scattering layer in the St. Lawrence estuary, principally composed of $C$. finmarchicus, left its day depth in mid-afternoon to reach the surface around $30 \mathrm{~min}$ later. The scattering layer then dispersed for the rest of the night with an increasing number of individuals being found in the lower strata. Gut pigment was found to increase rapidly during the first 2 to $3 \mathrm{~h}$ of the night in individuals found in both the upper and lower strata. Gut pigment levels decreased through the middle of the night and rose again towards dawn. The final descent of those individuals remaining at the surface was around 05:30 h. Durbin et al. (1995) observed a similar pattern at 2 stations in the Gulf of Maine. Gut pigments in animals found in the deep occurred as early as 20:00 h. Satiation-driven descent was advocated by each of these studies. However, none of them considered the location of potential predators and their respective times of arrival.

Evidence that krill in the Clyde Sea actively prey on copepods such as Calanus is clear. Lass et al. (2001) examined the stomachs and intestinal contents of Meganyctiphanes norvegica from this region over diel cycles and compared consumption levels to concentrations in the environment. Calanus was present in the guts of animals caught in the daytime at depth and in those found in the mid water column during the night. Generally, however, consumption levels of Calanus were lower than for other non-migrating copepod species, reflecting the ability of Calanus to avoid predation through midnight sinking. The same argument holds for Thysanoessa raschii, given that Mauchline (1966) also found Clyde Sea specimens with crustacean fragments in their stomachs.

To conclude, the Doppler vertical velocity anomaly revealed that Calanus performed midnight sinking to avoid krill consistently over a 3 mo period. Although it is likely that Calanus descended with food in their stomachs, it is clear that descent was a result of the avoidance of predation rather than satiation. The pattern resulted in Calanus spending a decreasing amount of time in the surface layers as the ascent of krill became increasingly earlier through the late summer. In this instance, the risk of predation appears to compromise their ability to feed in order to grow and store resources for overwintering.

Acknowledgements. We would like to thank C. Griffiths, M. Inall and the crew of the RV 'Calanus' for the logistics and support of the mooring operations, R. Saunders for help with field sampling and the processing of zooplankton samples, and I. Ezzi and K. Jones for provision of a fluorometer and the analysis of water bottle samples for chlorophyll a biomass. We are also grateful to P. Miller of Plymouth Marine Laboratory for provision of the SeaWiFS, which was originally acquired by the Dundee Satellite Recording Station courtesy of the NASA SeaWiFS project and Orbital Science Corporation. G.A.T. was funded by a NERC post-doctoral fellowship (GST/59818MS), T.J. by a Highlands and Islands Millenium Institute studentship and S.M.E. by a NERC thematic grant (Marine Productivity [I]; NER/T/S/1999/00067). 


\section{LITERATURE CITED}

Båmstedt U, Karlson K (1998) Euphausiid predation on copepods in coastal waters of the Northeast Atlantic. Mar Ecol Prog Ser 172:149-168

Boden BP, Kampa EM (1967) The influence of natural light on the vertical migration of an animal community in the sea. Symp Zool Soc 19:15-26

Cushing DH (1951) The vertical migration of planktonic crustacea. Biol Rev 26:158-192

Dalpadado P, Ellertsen B, Melle W, Skjoldal HR (1998) Summer distribution patterns and biomass estimates of macrozooplankton and micronekton in the Nordic Seas. Sarsia 83:103-116

Daro MH (1988) Migratory and grazing behavior of copepods and vertical distribution of phytoplankton. Bull Mar Sci $37: 487-497$

Deines KL (1999) Backscatter estimation using broadband acoustic Doppler current profilers. RD Instruments, San Diego

Durbin EG, Campbell RG, Gilman SL, Durbin AG (1995) Diel feeding behavior and ingestion rate in the copepod Calanus finmarchicus in the southern Gulf of Maine during the late spring. Cont Shelf Res 15:529-570

Fortier M, Fortier L, Hattori H, Saito H, Legendre L (2001) Visual predators and the diel vertical migration of copepods under Arctic sea ice during the midnight sun. J Plankton Res 23:1263-1278

Gardiner AC (1933) Vertical distribution of Calanus finmarchicus. J Mar Biol Assoc UK 18:575-610

Gauld DT (1953) Diurnal variation in the grazing of planktonic copepods. J Mar Biol Assoc UK 31:461-474

Greenlaw CF (1979) Acoustical estimate of zooplankton populations. Limnol Oceanogr 24:226-242

Hardy AC, Bainbridge R (1954) Experimental observations on the vertical migrations of planktonic animals. J Mar Biol Assoc UK 33:409-448

Heywood KJ (1996) Diel vertical migration of zooplankton in the Northeast Atlantic. J Plankton Res 18:163-184

Holm-Hansen O, Lorenzen CJ, Holmes RW, Strickland JDH (1965) Fluorometric determination of chlorophyll. J Cons Perm Int Explor Mer 30:3-15

Kils U (1981) Swimming behaviour, swimming performance and energy balance of Antarctic krill Euphausia superba. BIOMASS Scientific Series 3:1-121

Krause M, Radach G (1989) On the relations of vertical distribution, diurnal migration and nutritional state of herbivorous zooplankton in the northern North Sea during FLEX 1976. Int Rev Hydrobiol 74:371-417

Lass S, Tarling GA, Virtue P, Matthews JBL, Mayzaud P, Buchholz F (2001) On the food of Northern Krill (Meganyctiphanes norvegica) in relation to its vertical distribution. Mar Ecol Prog Ser 214:177-200

Longhurst A, Williams R (1979) Materials for plankton modelling: vertical distribution of Atlantic zooplankton in summer. J Plankton Res 1:1-28

Mackas D, Bohrer R (1976) Fluorescense analysis of zooplankton gut contents and an investigation of diel feeding patterns. J Exp Mar Biol Ecol 25:77-85

Mauchline J (1960) The biology of the euphausiid crustacean, Meganyctiphanes norvegica Sars. Proc R Soc Edinb Sect B (Biol Sci) 67:141-179

Mauchline J (1966) The biology of Thysanoessa raschii (M. Sars), with a comparison of its diet with that of Meganyctiphanes norvegica (M. Sars). In: Barnes H (ed) Some contemporary studies in marine sciences. George Allen \& Unwin, London, p 493-510

Michael EL (1911) Classification and vertical distribution of the Chaetognatha of the San Diego region. Univ Calif Publ Zool 8:1-21

Moore GF, Aiken J, Lavender SJ (1999) The atmospheric correction of water colour and the quantitative retrieval of suspended particulate matter in Case II waters: application to MERIS. Int J Remote Sens 20:1713-1733

O'Reilly JR, Maritorena S, Mitchell BG, Siegel DA, Carder KL, Garver SA, Kahru M, McClain C (1998) Ocean color chlorophyll algorithms for SeaWiFS. J Geophys Res 103: 24937-24953

Pearre S (1973) Vertical migration and feeding in Sagitta elegans (Verrill). Ecology 54:300-314

Pearre S (1979) On the adaptive significance of vertical migration. Limnol Oceanogr 24:781-782

Pinot JM, Jansa J (2001) Time variability of acoustic backscatter from zooplankton in the Ibiza Channel (western Mediterranean). Deep-Sea Res II 48:1651-1670

Pleuddemann AJ, Pinkel R (1989) Characterization of the patterns of diel migration using a Doppler sonar. Deep-Sea Res 36:509-530

Ringelberg J (1995) Changes in light-Intensity and diel vertical migration - a comparison of marine and fresh-water environments. J Mar Biol Assoc UK 75:15-25

Roe HSJ, James PT, Thurston MH (1984) The diel migrations and distributions within a mesopelagic community in the North East Atlantic 6. Medusae, ctenophores, amphipods and euphausiids. Prog Oceanogr 13:425-460

Sameoto DD (1980) Relationships between stomach contents and vertical migration in Meganyctiphanes norvegica, Thysanoessa raschii and T. inermis (Crustacea: Euphausiacea). J Plankton Res 2:129-143

Simard Y, Lacroix G, Legendre L (1985) In-situ twilight grazing rhythm during diel vertical migrations of a scattering layer of Calanus finmarchicus. Limnol Oceanogr 30:598-606

Simard Y, Ladurantaye RD, Therriault JC (1986) Aggregation of euphausiids along a coastal shelf in an upwelling environment. Mar Ecol Prog Ser 32:203-215

Skreslet S, Olsen K, Mohus A, Tande KS (2000) Stage-specific habitats of Calanus finmarchicus and Calanus helgolandicus in a stratfied northern Norwegian fjord. ICES J Mar Sci 57:1656-1663

Tarling GA, Buchholz F, Matthews JBL (1999) The effect of a lunar eclipse on the vertical migration of Meganyctiphanes norvegica (Crustacea: Euphausiacea) in the Ligurian Sea. J Plankton Res 21:1475-1488

Tarling GA, Matthews JBL, David P, Guerin O, Buchholz F (2001) The swarm dynamics of Northern krill (Meganyctiphanes norvegica) and pteropods (Cavolinia inflexa) during vertical migration in the Ligurian Sea observed by an Acoustic Doppler Current Profiler. Deep-Sea Res I 48: 1671-1686

Torgersen T (2001) Visual predation by the euphausiid Meganyctiphanes norvegica. Mar Ecol Prog Ser 209:295-299

Wang R, Conover RJ (1986) Dynamics of gut pigment in the copepod Temora longicornis and the determination of in situ grazing rates. Limnol Oceanogr 31:867-877

Wiebe PH, Morton AW, Bradley AM, Backus RH, Craddock JE, Barber V, Cowles TJ, Flierl GR (1985) New developments in the MOCNESS, an apparatus for sampling zooplankton and micronekton. Mar Biol 87:313-323

Wiebe PH, Copley NJ, Boyd SH (1992) Coarse-scale horizontal patchiness and vertical migration of zooplankton in Gulf Stream warm-core ring 82-H. Deep-Sea Res 39 (Suppl): S247-S278

Wright DI, O'Brien WJ (1984) The development and field test of a tactical model of the planktivorous feeding of white crappie (Pomoxis annularis). Ecol Monogr 54:65-98

Submitted: November 15, 2001; Accepted: April 23, 2002

Proofs received from author(s): August 12, 2002 